\title{
Correction to: Forecasting Content and Stage in a Nursing Home Information Technology Maturity Instrument Using a Delphi Method
}

\section{Gregory L. Alexander ${ }^{1}$ (D) Chelsea Deroche ${ }^{2} \cdot$ Kimberly Powell $^{3} \cdot$ Abu Saleh Mohammad Mosa $^{4} \cdot$ Lori Popejoy $^{3}$. Richelle Koopman ${ }^{5}$}

Published online: 26 February 2020

(C) Springer Science+Business Media, LLC, part of Springer Nature 2020

Correction to: Journal of Medical Systems.

https://doi.org/10.1007/s10916-020-1528-6

The original article unfortunately contained a mistake. The name of the 4th author should be listed as "Abu Saleh Mohammad Mosa". The last name "Mosa" was omitted.

Gregory L. Alexander

AlexanderG@missouri.edu

1 S415 Sinclair School of Nursing, University of Missouri Columbia, Columbia, MO 65211-6000, USA

2 Office of Medical Research, University of Missouri Columbia, Columbia, MO 65211-6000, USA

3 Sinclair School of Nursing, University of Missouri Columbia, Columbia, MO 65211-6000, USA

4 School of Medicine, University of Missouri Columbia, Columbia, MO 65211-6000, USA

5 Family and Community Medicine, University of Missouri, Columbia, MO 65211, USA 